\title{
An assessment of the relation between vitamin D levels and electroencephalogram (EEG) changes in migraine patients
}

\author{
Canpolat $\mathrm{M}^{1}$, Topcu $\mathrm{A}^{2}$, Kardas $\mathrm{F}^{3}$, Ipekten $\mathrm{F}^{4}$, Per $\mathrm{H}^{1}$, Gumus $\mathrm{H}^{1}$, Ozturk $\mathrm{A}^{4}$, Acer $\mathrm{H}^{1}$, \\ Kaya Ozcora $\mathrm{GD}^{1}$, Kendirci $\mathrm{M}^{3}$, Kumandas $\mathrm{S}^{1}$ \\ Department of Pediatrics, Division of Pediatric Neurology, Erciyes University School of Medicine, \\ Kayseri, Turkey. mcanpolat@erciyes.edu.tr
}

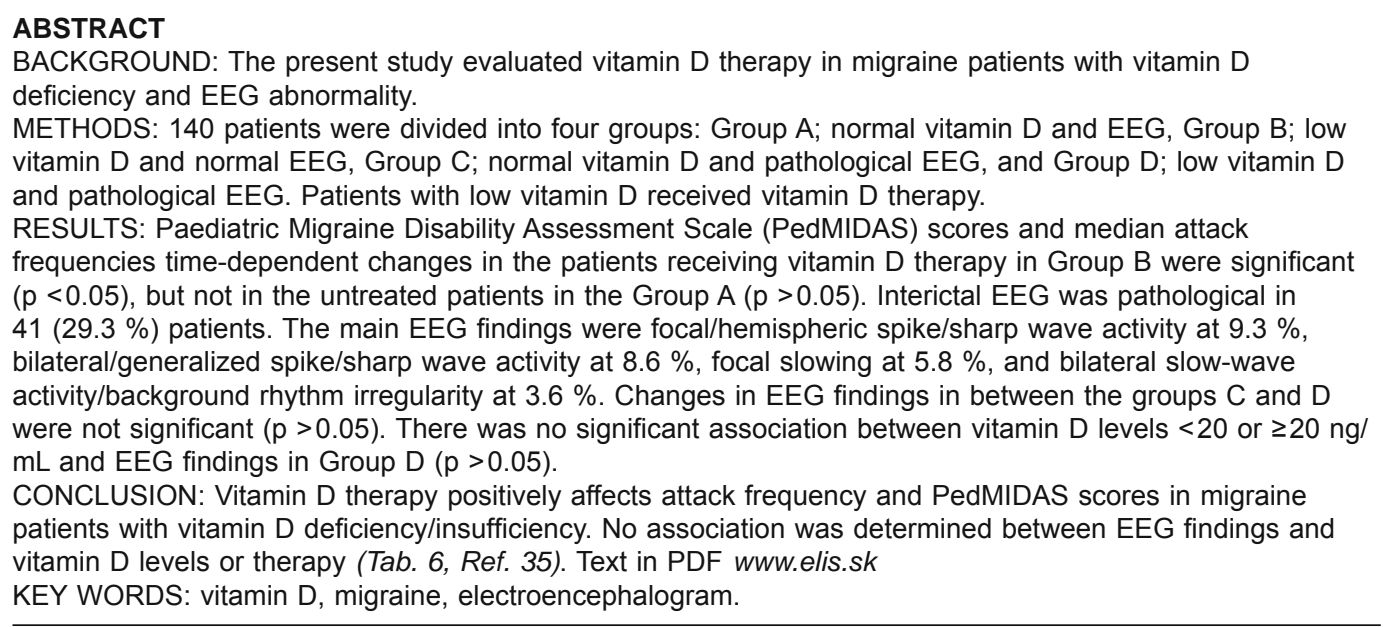

\section{Introduction}

Migraine is the most common cause of chronic and repetitive headache in childhood $(1,2)$. Despite many conducted studies, it was not possible to explain migraine etiopathogenesis with a single theory. The main pathology in migraine is considered to be the existence of an over-excitable cerebral cortex (2)

Epileptiform abnormalities are detected in EEG of migraine patients due to overexcitable cortex, and this comorbid condition may sometimes cause misdiagnosis (3). Neuronal hyperexcitability and cortical spreading depression (CSD) were considered to be

${ }^{1}$ Department of Pediatric, Division of Neurology, Erciyes University School of Medicine, Kayseri, Turkey, ${ }^{2}$ Department of Pediatrics, Erciyes University School of Medicine, Kayseri, Turkey, ${ }^{3}$ Department of Pediatrics, Division of Metabolism, Erciyes University School of Medicine, Kayseri, Turkey, and ${ }^{4}$ Department of Biostatistics, Erciyes University School of Medicine, Kayseri, Turkey, and Turcosa Analytics Solutions Ltd.Co., Kayseri, Turkey

Address for correspondence: M. Canpolat, Prof, Department of Pediatrics, Division of Pediatric Neurology, Erciyes University School of Medicine, Kayseri, Turkey. Phone: +90.352.2076666

Funding: This study was supported by the TÜBİTAK for supporting this work with the project numbered 116S042 with Program Code 3001 for their support. responsible for the relationship between epilepsy and migraine, however, etiopathogenesis has not been fully clarified (3).

It is known that Vitamin D, as a neurosteroid, has a modulating effect on neuronal hyperexcitability and predisposition to convulsion. It is stated that it plays a regulatory role in excitability with its modulating effect on gamma-aminobutyric acid (GABA) (A) receptor (4-6).

Therefore, the present study had been carried out to evaluate vitamin $\mathrm{D}$ levels in migraine patients and the efficiency of vitamin D therapy on the patients, who had vitamin D deficiency and EEG abnormalities.

\section{Methods}

The present study was approved by Erciyes University Faculty of Medicine Ethical Committee under decision no.2015/489 dated 25.11.2015. It was supported by The Scientific and Technological Research Council of Turkey (TÜBİTAK) with programme code 3001 and project number 116 S042. Erciyes University Pediatric Neurology clinic with a headache and diagnosed with migraine with/without aura according to International Classification of Headache Disorders (ICHD)-III beta were included in the study. Informed consent for the study was taken from the guardians of all the patients participating in the study. 
Study design

Patients were divided into four groups according to vitamin D level and EEG findings.

Group A; patients, who had normal vitamin D levels and EEG findings. Classical migraine prophylaxis therapies such as: flunarizine, topiramate and valproate were initiated considering the accompanying clinical findings for the patients, who need migraine prophylaxis therapies.

Group B; patients, who had low vitamin D and normal EEG findings. Initially, vitamin D was applied to patients in Group $\mathrm{B}$ for migraine prophylaxis.

Group C; patients, who had normal vitamin D level and pathological EEG findings. Classical migraine prophylaxis therapies were initiated considering the accompanying clinical findings for the patients, who need migraine prophylaxis therapies.

Group D; patients, who had low vitamin $\mathrm{D}$ and pathologic EEG findings. Initially, vitamin D was given to the patients in Group $\mathrm{D}$ for migraine prophylaxis.

All the patients were examined using the Pediatric Migraine Disability Assessment Scale (PedMIDAS) for migraine disability at the initial diagnosis, at 3,6 and 12 months (7). The frequency of attacks and response to treatment in the clinical follow-up of patients were evaluated at 1 , 3,6 and 12 months.

In Group B and D, patients, who initially had vitamin $\mathrm{D}$ treatment ineffective and who needed migraine prophylaxis despite vitamin D treatment in their follow-ups were given classical migraine prophylaxis therapies.

At the end of the study, the effects of vitamin $\mathrm{D}$ on attack frequency and clinical findings were evaluated by comparing the attack frequency and clinical findings of the group A and group B. The effects of vitamin D on EEG findings were evaluated by comparing EEG findings and treatment responses of group C and group D.

Determining Vitamin D levels

At baseline, plasma $25(\mathrm{OH}) \mathrm{D}$ levels of all the patients were evaluated with HPLC (high-pressure liquid chromatography) method using ClinRep Kit (IRIS Technologies International GmbH, Cursdorf, Germany). Both vitamin D levels and clinical responses to treatment of patients, who had vitamin D deficiency were evaluated at 1, 3,6 and 12 months.
Tab. 1. Comparison of patients who completed the study according to patient groups, gender, age, Vitamin D, Ca, P, PTH values according to groups at baseline and migraine type variables.

\begin{tabular}{|c|c|c|c|c|c|}
\hline \multirow{2}{*}{ Parameters } & \multicolumn{4}{|c|}{ Patient groups } & \multirow{2}{*}{$\mathrm{p}$} \\
\hline & $\mathrm{A}$ & B & $\mathrm{C}$ & $\mathrm{D}$ & \\
\hline \multicolumn{6}{|l|}{ Gender } \\
\hline Female & $17(39.5)^{\mathrm{a}}$ & $38(67.9)^{\mathrm{a}}$ & $8(53.3)^{\mathrm{a}}$ & $16(61.5)^{\mathrm{a}}$ & \multirow[t]{2}{*}{0.039} \\
\hline Male & $26(60.5)^{b}$ & $18(32.1)^{b}$ & $7(46.7)^{\mathrm{a}}$ & $10(38.5)^{\mathrm{a}}$ & \\
\hline Age & $12.80 \pm 2.87$ & $13.05 \pm 2.98$ & $12.15 \pm 3.13$ & $12.74 \pm 2.09$ & 0.744 \\
\hline $\begin{array}{l}\text { Vitamin D } \\
\text { (ng/mL) }\end{array}$ & $\begin{array}{c}26.55 \pm 6.50^{\mathrm{a}} \\
(20.21-48.97) \\
\end{array}$ & $\begin{array}{l}13.13 \pm 3.82^{\mathrm{b}} \\
(3.82-19.94)\end{array}$ & $\begin{array}{c}27.31 \pm 5.58^{\mathrm{a}} \\
(20.54-39.49) \\
\end{array}$ & $\begin{array}{l}13.84 \pm 4.19^{\mathrm{b}} \\
(4.66-19.84) \\
\end{array}$ & $<0.001$ \\
\hline $\mathrm{Ca}(\mathrm{mg} / \mathrm{dL})$ & $\begin{array}{c}9.81 \pm 0.38 \\
(8.99-10.67) \\
\end{array}$ & $\begin{array}{l}9.81 \pm 0.28 \\
(9.18-10.39) \\
\end{array}$ & $\begin{array}{c}9.83 \pm 0.36 \\
(9.32-10.59) \\
\end{array}$ & $\begin{array}{c}9.84 \pm 0.43 \\
(9.01-10.67) \\
\end{array}$ & 0.974 \\
\hline $\mathrm{P}(\mathrm{mg} / \mathrm{dL})$ & $\begin{array}{l}4.49 \pm 0.73 \\
(2.86-5.68)\end{array}$ & $\begin{array}{c}4.55 \pm 0.69 \\
(3.19-6.03)\end{array}$ & $\begin{array}{l}4.48 \pm 0.70 \\
(3.30-5.80)\end{array}$ & $\begin{array}{c}4.69 \pm 0.71 \\
(3.24-6.15)\end{array}$ & 0.685 \\
\hline PTH (pg/mL) & $\begin{array}{l}41.61 \pm 17.14 \\
(9.97-103.90) \\
\end{array}$ & $\begin{array}{c}45.52 \pm 21.10 \\
(15.02-101.90) \\
\end{array}$ & $\begin{array}{c}36.29 \pm 9.97 \\
(24.82-57.92) \\
\end{array}$ & $\begin{array}{c}52.70 \pm 49.86 \\
(15.04-264.90) \\
\end{array}$ & 0.236 \\
\hline \multicolumn{6}{|l|}{ Migraine type } \\
\hline With aura & $11(25.6)$ & $21(37.5)$ & $6(40.0)$ & $12(46.2)$ & \multirow[t]{2}{*}{0.268} \\
\hline Without aura & $32(74.4)$ & $35(62.5)$ & $9(60.0)$ & $14(53.8)$ & \\
\hline
\end{tabular}

Data are given as mean \pm standard deviation and $\mathrm{n}(\%) . * *$ Values in the parentheses represent minimum and maximum values. According to the multiple comparison test, the same letters in the same column express the similarity between the groups and the different letters express a difference.

Tab. 2. Comparison of PedMIDAS scores and attack frequencies between groups and by time.

\begin{tabular}{|c|c|c|c|c|c|}
\hline \multirow[b]{2}{*}{ Variables } & \multicolumn{4}{|c|}{ Groups } & \multirow[b]{2}{*}{ p* } \\
\hline & $\underset{(n=43)}{A}$ & $\begin{array}{c}\mathrm{B} \\
(\mathrm{n}=56)\end{array}$ & $\begin{array}{c}\mathrm{C} \\
(\mathrm{n}=15)\end{array}$ & $\begin{array}{c}\mathrm{D} \\
(\mathrm{n}=26)\end{array}$ & \\
\hline $\begin{array}{l}\text { Baseline } \\
\text { PedMIDAS }\end{array}$ & $11.0(3.0-24.0)^{\mathrm{a}}$ & $14.5(6.0-33.8)^{\mathrm{a}}$ & $9.0(6.0-24.0)^{\mathrm{a}}$ & $13.5(0.8-35.5)^{\mathrm{a}}$ & 0.425 \\
\hline $\begin{array}{l}\text { 3rd month } \\
\text { PedMIDAS }\end{array}$ & $5.0(2.0-12.0)^{\mathrm{ab}}$ & $9.5(0.0-20.8)^{\mathrm{ab}}$ & $0.0(0.0-4.0)^{\mathrm{ab}}$ & $6.0(0.0-16.5)^{\mathrm{ab}}$ & 0.114 \\
\hline $\begin{array}{l}\text { 6th month } \\
\text { PedMIDAS }\end{array}$ & $4.0(1.0-20.0)^{\mathrm{ab}}$ & $4.0(0.0-14.0)^{b}$ & $1.0(0.0-14.0)^{\mathrm{ab}}$ & $2.5(0.0-14.0)^{b}$ & 0.235 \\
\hline $\begin{array}{l}\text { 12th month } \\
\text { PedMIDAS }\end{array}$ & $4.0(0.0-11.0)^{\mathrm{b}}$ & $8.0(0.0-13.0)^{b}$ & $1.0(0.0-8.0)^{\mathrm{b}}$ & $1.0(0.0-6.0)^{b}$ & 0.140 \\
\hline $\mathrm{p}$ & 0.003 & $<0.001$ & 0.023 & $<0.001$ & \\
\hline \multirow[b]{2}{*}{ Variables } & \multicolumn{4}{|c|}{ Groups } & \\
\hline & $\begin{array}{c}\mathrm{A} \\
(\mathrm{n}=43)\end{array}$ & $\begin{array}{c}\mathrm{B} \\
(\mathrm{n}=56)\end{array}$ & $\begin{array}{c}\mathrm{C} \\
(\mathrm{n}=15)\end{array}$ & $\begin{array}{c}\mathrm{D} \\
(\mathrm{n}=26)\end{array}$ & p* \\
\hline $\begin{array}{l}\text { Baseline frequency } \\
\text { of attacks }\end{array}$ & $4.0(3.0-10.0)^{\mathrm{a}}$ & $6.5(4.0-12.0)^{\mathrm{a}}$ & $4.0(2.0-12.0)$ & $4.0(2.8-10.0)^{\mathrm{a}}$ & 0.116 \\
\hline $\begin{array}{l}\text { 1st month frequency } \\
\text { of attacks }\end{array}$ & $3.0(1.0-6.0)^{b}$ & $4.0(2.0-6.8)^{b}$ & $2.0(1.0-10.0)$ & $3.0(1.0-4.0)^{\mathrm{ab}}$ & 0.343 \\
\hline $\begin{array}{l}\text { 3rd month frequency } \\
\text { of attacks }\end{array}$ & $3.0(1.0-4.0)^{\mathrm{b}}$ & $3.5(2.0-7.8)^{b}$ & $2.0(0.0-4.0)$ & $3.0(1.8-5.3)^{\mathrm{ab}}$ & 0.092 \\
\hline $\begin{array}{l}\text { 6th month frequency } \\
\text { of attacks }\end{array}$ & $3.0(1.0-5.0)^{b}$ & $3.0(1.0-6.0)^{b}$ & $1.0(1.0-3.0)$ & $3.0(1.0-4.0)^{\mathrm{ab}}$ & 0.328 \\
\hline $\begin{array}{l}\text { 12th month frequency } \\
\text { of attacks }\end{array}$ & $3.0(1.0-4.0)^{b}$ & $3.0(1.0-4.8)^{\mathrm{b}}$ & $2.0(1.0-6.0)$ & $1.5(1.0-3.3)^{b}$ & 0.622 \\
\hline p & 0.002 & $<0.001$ & 0.124 & 0.001 & \\
\hline
\end{tabular}

Data are expressed as median (1st quarter-3rd quarter). According to the multiple comparison test, the same letters in the same column express the similarity between the groups and the different letters express a difference. p; shows the significance of difference between time periods and $\mathrm{p}^{*}$ shows the significancy of difference between groups.

\section{Vitamin D therapy}

Patients with a plasma $25(\mathrm{OH})$ D level below $<12 \mathrm{ng} / \mathrm{mL}$ were evaluated as vitamin D deficiency, and those found between $12-20 \mathrm{ng} / \mathrm{mL}$ as vitamin D insufficiency (8). After the routine etiological evaluation, 150.000 IU single-dose oral vitamin D 
Tab. 3. Comparison of PedMIDAS scores and frequency of attacks between the patients who received treatment in group $A$ and those who received vitamin $D$ in group $B$, and those who + the treatment in the group $A$ and those who received the vitamin $D$ in the group $B$, according to the time and frequency of attacks.

\begin{tabular}{|c|c|c|c|}
\hline \multirow[b]{2}{*}{ Variables } & \multicolumn{2}{|c|}{ Groups } & \multirow[b]{2}{*}{$\mathrm{p}^{*}$} \\
\hline & $\begin{array}{l}\text { Patients who received } \\
\text { treatment* in group A } \\
(\mathrm{n}=26)\end{array}$ & $\begin{array}{c}\text { Patients who received } \\
\text { Vitamin } \mathrm{D} \text { in group B } \\
(\mathrm{n}=56)\end{array}$ & \\
\hline Baseline PedMIDAS & $18.5(9.5-29.3)^{\mathrm{a}}$ & $14.5(6.0-33.8)^{\mathrm{a}}$ & 0.716 \\
\hline 3rd month PedMIDAS & $5.0(1.8-12.3)^{\mathrm{b}}$ & $9.5(0.0-20.8)^{\mathrm{ab}}$ & 0.597 \\
\hline 6th month PedMIDAS & $6.5(1.8-12.3)^{\mathrm{b}}$ & $4.0(0.0-14.0)^{\mathrm{b}}$ & 0.371 \\
\hline 12th month PedMIDAS & $3.0(0.0-11.3)^{\mathrm{b}}$ & $8.0(0.0-13.0)^{\mathrm{b}}$ & 0.730 \\
\hline p & $<0.001$ & $<0.001$ & \\
\hline Baseline frequency of attacks & $8.0(4.0-12.0)^{\mathrm{a}}$ & $6.5(4.0-12.0)^{\mathrm{a}}$ & 0.684 \\
\hline 1st month frequency of attack & $3.5(1.0-6.5)^{b}$ & $4.0(2.0-6.8)^{\mathrm{b}}$ & 0.362 \\
\hline 3rd month frequency of attack & $3.0(1.0-4.0)^{\mathrm{b}}$ & $3.5(2.0-7.8)^{b}$ & 0.103 \\
\hline 6th month frequency of attack & $3.0(1.0-6.5)^{\mathrm{b}}$ & $3.0(1.0-6.0)^{\mathrm{b}}$ & 0.868 \\
\hline 12th month frequency of attack & $3.0(1.0-4.0)^{\mathrm{b}}$ & $3.0(1.0-4.8)^{\mathrm{b}}$ & 0.940 \\
\hline \multirow[t]{2}{*}{$\mathrm{p}$} & $<0.001$ & $<0.001$ & \\
\hline & \multicolumn{2}{|c|}{ Groups } & \\
\hline Variables & $\begin{array}{l}\text { Patients who did not received } \\
\text { treatment* in group A } \\
(\mathrm{n}=17)\end{array}$ & $\begin{array}{c}\text { Patients who received } \\
\text { vitamin } \mathrm{D} \text { in group } \mathrm{B} \\
(\mathrm{n}=56)\end{array}$ & $\mathrm{p}^{*}$ \\
\hline Baseline PedMIDAS & $5.0(3.0-10.5)$ & $14.5(6.0-33.8)^{\mathrm{a}}$ & 0.004 \\
\hline 3rd month PedMIDAS & $5.0(2.0-14.0)$ & $9.5(0.0-20.8)^{\mathrm{ab}}$ & 0.509 \\
\hline 6th month PedMIDAS & $4.0(0.0-16.0)$ & $4.0(0.0-14.0)^{\mathrm{b}}$ & 0.947 \\
\hline 12th month PedMIDAS & $5.0(0.0-7.5)$ & $8.0(0.0-13.0)^{\mathrm{b}}$ & 0.545 \\
\hline p & 0.908 & $<0.001$ & \\
\hline Baseline frequency of attack & $3.0(2.0-4.0)$ & $6.5(4.0-12.0)^{\mathrm{a}}$ & 0.001 \\
\hline 1 st month frequency of attack & $3.0(1.0-6.0)$ & $4.0(2.0-6.8)^{b}$ & 0.458 \\
\hline 3rd month frequency of attack & $3.0(1.5-4.0)$ & $3.5(2.0-7.8)^{\mathrm{b}}$ & 0.169 \\
\hline 6th month frequency of attack & $4.0(1.0-4.5)$ & $3.0(1.0-6.0)^{\mathrm{b}}$ & 0.757 \\
\hline 12th month frequency of attack & $3.0(1.0-6.5)$ & $3.0(1.0-4.8)^{\mathrm{b}}$ & 0.777 \\
\hline p & 0.996 & $<0.001$ & \\
\hline
\end{tabular}

Data are expressed as median (1st quarter-3rd quarter). According to the multiple comparison test, the same letters in the same column express the similarity between the groups and the different letters express a difference. $p$; shows the significance of difference between time periods and $p^{*}$ shows the significancy of difference between groups. Treatment* Drug treatments such as flunarizine, topiramate, valproate used in the treatment of migraine prophylaxis.

(stoss therapy) was applied and vitamin D levels were increased to $20 \mathrm{ng} / \mathrm{mL}(8)$.

\section{EEG}

All scans were performed using 21 electrodes and 10-20 system adhered to the scalp with paste with Grass (R) AS40 and/ or AS40 Plus (Astro-Med, U.S.A.) and/or Nihon Kohden EEG1200K (Nihon Kohden Corporation, Japan) and/or Natus Nicolet EEG v32 (Natus Neurology Incorporated, U.S.A) EEG devices. According to EEG findings, patients were defined as with normal EEG findings and with pathological EEG findings.

\section{Statistical analysis}

The suitability of data for normal distribution was evaluated by histogram and Q-Q plots and Shapiro-Wilk test. The homogeneity of the variances was tested with Levene's test. Mann-Whitney $U$ test and two-sample independent t-test were used to compare the quantitative parameters between the groups. Kruskal Wallis test was used for the comparisons between more than two groups. Friedman test was applied for comparison of quantitative para- meters between the measurements. For multiple comparisons, Dunn-Bonferroni and Adjusted Bonferroni tests were applied. Pearson $\chi 2$ analysis was used for comparison of categorical data. Cochran's Q test was used for qualitative variables in comparisons between measurements. Analysis of data was performed in TURCOSA (Turcosa Ltd Co, ) statistical software. Significance level was set as $\mathrm{p}<0.05$.

\section{Results}

There was a total of 140 patients, 79 (56.4\%) girls and 61 (43.6\%) boys, who completed the study. Fifty of the patients (35.7\%) had migraine with aura while 90 patients $(64.3 \%)$ had migraine without aura. Ninety-nine of the patients $(70.7 \%)$ had normal EEG findings while 41 of the patients $(29.3 \%)$ had pathological EEG findings.

No statistically significant difference was found between the patient groups for age and migraine type $(p>0.05)$. Statistically significant difference was found between the patient group and gender $(\mathrm{p}<0.05)$. In group $\mathrm{A}$, the number of male patients was significantly higher than the number of female patients. In group B, the number of female patients was significantly higher than the number of male patients. Table 1 shows the distribution of age, gender and migraine type parameters between the study groups. At baseline, a statistically significant difference was found between the mean values of vitamin $\mathrm{D}$ levels of patients in all the groups $(\mathrm{p}<0.05)$ (Tab. 1).

In Table 2, PedMIDAS scores and the comparison of the frequency of attacks between groups and periods are presented. PedMIDAS score was not statistically significant between groups at baseline, 3rd month, 6th month and 12th month ( $\mathrm{p}>0.05)$. While the change of attack frequency in the group over time was not statistically significant in group C ( $p>0.05)$, the change of PedMIDAS scores over time was significant $(\mathrm{p}<0.05)$.

No statistically significant difference was found within the groups over time for patients, who received treatment in group A and patients, who received vitamin $\mathrm{D}$ in group B for baseline, 3, 6 and 12 months PedMIDAS scores and for the frequency of attack at baseline, 1, 3, 6 and 12 months ( $p>0.05)$ (Tab. 3). A statistically significant difference was found between the groups, who did not receive treatment in the A group at the beginning and who received vitamin D in the group B for the frequency of attacks at baseline $(p<0.05)$. Time-dependent changes in the frequency of attack at baseline, 1st, 3rd, 6th and 12th months of the group, who did not receive treatment in group $\mathrm{A}$ at the beginning were not statistically 
Tab. 4. Comparison of PedMIDAS scores and attack frequencies of patients in group B who completed the study between subgroups of vitamin $D$.

\begin{tabular}{|c|c|c|c|}
\hline \multirow[b]{2}{*}{ Variables } & \multicolumn{3}{|c|}{ Frequency of attacks of patients in group B at 1st month } \\
\hline & $\begin{array}{c}\text { Vitamin D level }<20 \mathrm{ng} / \mathrm{mL} \\
(\mathrm{n}=17)\end{array}$ & $\begin{array}{c}\text { Vitamin D level } \geq 20 \mathrm{ng} / \mathrm{mL} \\
(\mathrm{n}=39)\end{array}$ & $\mathrm{p}^{*}$ \\
\hline Baseline frequency of attacks & $8.0(3.5-13.5)^{\mathrm{a}}$ & $5.0(4.0-12.0)^{\mathrm{a}}$ & 0.726 \\
\hline 1st month frequency of attacks & $5.0(3.0-11.0)^{\mathrm{ab}}$ & $3.0(2.0-6.0)^{\mathrm{b}}$ & 0.041 \\
\hline 3rd month frequency of attacks & $5.0(2.0-9.0)^{\mathrm{ab}}$ & $3.0(2.0-6.0)^{\mathrm{ab}}$ & 0.374 \\
\hline 6th month frequency of attacks & $4.0(1.5-11.0)^{\mathrm{ab}}$ & $2.0(1.0-5.0)^{\mathrm{b}}$ & 0.102 \\
\hline 12 th month frequency of attacks & $3.0(1.0-4.5)^{\mathrm{b}}$ & $3.0(1.0-5.0)^{\mathrm{b}}$ & 0.607 \\
\hline$\underline{\mathrm{p}}$ & 0.003 & $<0.001$ & \\
\hline \multirow{2}{*}{ Variables } & \multicolumn{3}{|c|}{$\begin{array}{c}\text { Frequency of attacks and PedMIDAS scores of patients in } \\
\text { group B at 3rd month }\end{array}$} \\
\hline & $\begin{array}{c}\text { Vitamin D level }<20 \mathrm{ng} / \mathrm{mL} \\
(\mathrm{n}=18)\end{array}$ & $\begin{array}{c}\text { Vitamin D level } \geq 20 \mathrm{ng} / \mathrm{mL} \\
(\mathrm{n}=38)\end{array}$ & $\mathrm{p}^{*}$ \\
\hline Baseline PedMIDAS & $16.0(6.8-30.0)$ & $13.0(5.0-35.0)^{\mathrm{a}}$ & 0.550 \\
\hline 3rd month PedMIDAS & $13.5(2.3-21.8)$ & $7.0(0.0-18.0)^{\mathrm{ab}}$ & 0.179 \\
\hline 6th month PedMIDAS & $4.0(0.0-15.0)$ & $4.0(0.0-13.0)^{\mathrm{b}}$ & 0.283 \\
\hline 12th month PedMIDAS & $1.0(0.0-10.0)$ & $9.0(0.015 .8)^{\mathrm{b}}$ & 0.105 \\
\hline $\mathrm{P}$ & 0.054 & $<0.001$ & \\
\hline Baseline frequency of attack & $5.0(4.0-12.8)^{\mathrm{a}}$ & $7.5(3.8-12)^{\mathrm{a}}$ & 0.958 \\
\hline 1st month frequency of attack & $4.0(2.8-10.0)^{\mathrm{ab}}$ & $3.0(2.0-6.0)^{\mathrm{ab}}$ & 0.479 \\
\hline 3rd month frequency of attack & $3.5(2.8-7.3)^{\mathrm{ab}}$ & $3.5(2.0-8.0)^{\mathrm{ab}}$ & 0.791 \\
\hline 6th month frequency of attack & $3.0(1.0-5.0)^{\mathrm{b}}$ & $3.0(1.0-6.5)^{\mathrm{b}}$ & 0.811 \\
\hline 12th month frequency of attack & $2.5(0.0-7.5)^{\mathrm{b}}$ & $3.0(1.0-4.0)^{\mathrm{b}}$ & 0.122 \\
\hline
\end{tabular}

\begin{tabular}{|c|c|c|c|}
\hline \multirow{3}{*}{ Variables } & 0.001 & $<0.001$ & \\
\hline & \multicolumn{3}{|c|}{$\begin{array}{l}\text { Frequency of attacks and PedMIDAS scores of patients in } \\
\text { group B at 6th month }\end{array}$} \\
\hline & \multicolumn{2}{|c|}{ 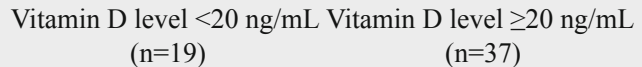 } & $\mathrm{p}^{*}$ \\
\hline Baseline PedMIDAS & $7.0(3.0-34.0)$ & $15.0(10.0-34.0)^{\mathrm{a}}$ & 0.077 \\
\hline 3rd month PedMIDAS & $18.0(0.0-24.0)$ & $19.0(0.0-15.0)^{\mathrm{a}}$ & 0.334 \\
\hline 6th month PedMIDAS & $4.0(0.0-15.0)$ & $4.0(0.0-13.0)^{\mathrm{b}}$ & 0.707 \\
\hline 12th month PedMIDAS & $2.0(0.0-14.0)$ & $8.0(0.0-13.0)^{\mathrm{b}}$ & 0.698 \\
\hline p & 0.129 & $<0.001$ & \\
\hline Baseline frequency of attacks & $4.0(3.0-12.0)^{\mathrm{a}}$ & $8.0(4.0-12.5)^{\mathrm{a}}$ & 0.253 \\
\hline 1st month frequency of attacks & $3.0(2.0-13.0)^{\mathrm{ab}}$ & $4.0(2.0-6.0)^{\mathrm{b}}$ & 0.965 \\
\hline 3rd month frequency of attacks & $6.0(2.0-10.0)^{\mathrm{ab}}$ & $3.0(2.0-5.5)^{\mathrm{b}}$ & 0.226 \\
\hline 6th month frequency of attacks & $3.0(1.0-5.0)^{\mathrm{b}}$ & $3.0(1.0-6.5)^{\mathrm{b}}$ & 0.583 \\
\hline 12th month frequency of attacks & $4.0(0.0-10.0)^{\mathrm{b}}$ & $3.0(1.0-4.0)^{\mathrm{b}}$ & 0.500 \\
\hline & 0.010 & $<0.001$ & \\
\hline
\end{tabular}

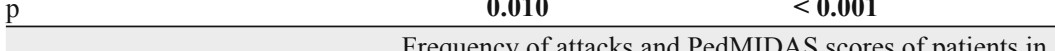

\begin{tabular}{lccc} 
Variables & \multicolumn{3}{c}{ group B at 12th month } \\
\cline { 2 - 4 } & $\begin{array}{c}\text { Vitamin D level }<20 \mathrm{ng} / \mathrm{mL} \text { Vitamin D level } \geq 20 \mathrm{ng} / \mathrm{mL} \\
(\mathrm{n}=16)\end{array}$ & $\mathrm{p}^{*}$ \\
\hline Baseline PedMIDAS & $13.0(7.3-23.5)^{\mathrm{a}}$ & $15.0(6.0-35.0)^{\mathrm{a}}$ & 0.580 \\
3rd month PedMIDAS & $10.0(0.0-20.8)^{\mathrm{ab}}$ & $9.5(0.5-20.3)^{\mathrm{ab}}$ & 0.568 \\
6th month PedMIDAS & $3.0(2.0-12.5)^{\mathrm{ab}}$ & $4.5(0.3-14.8)^{\mathrm{b}}$ & 0.318 \\
12th PedMIDAS & $1.0(0.0-10.0)^{\mathrm{b}}$ & $9.0(0.0-15.8)^{\mathrm{b}}$ & 0.073 \\
\hline $\mathrm{p}$ & $\mathbf{0 . 0 0 9}$ & $<\mathbf{0 . 0 0 1}$ & \\
\hline Baseline frequency of attacks & $4.5(3.3-8.0)^{\mathrm{a}}$ & $10.5(4.0-12.8)^{\mathrm{a}}$ & 0.107 \\
1st month frequency of attacks & $3.0(2.0-4.8)^{\mathrm{ab}}$ & $4.0(2.0-9.0)^{\mathrm{bc}}$ & 0.125 \\
3rd month frequency of attacks & $2.5(1.3-6.0)^{\mathrm{b}}$ & $4.0(3.0-8.0)^{\mathrm{ab}}$ & 0.125 \\
6th month frequency of attacks & $3.0(0.3-5.8)^{\mathrm{ab}}$ & $3.0(1.3-7.0)^{\mathrm{bc}}$ & 0.443 \\
12th month frequency of attacks & $2.5(0.0-7.5)^{\mathrm{ab}}$ & $3.0(1.0-4.0)^{\mathrm{c}}$ & 0.862 \\
\hline $\mathrm{p}$ & $\mathbf{0 . 0 4 6}$ & $<\mathbf{0 . 0 0 1}$ & \\
\hline
\end{tabular}

Data are expressed as median (1st quarter-3rd quarter) p; shows the significance of difference between time periods and $\mathrm{p}^{*}$ shows the significancy of difference between groups. According to the multiple comparison test, the same letters in the same column express the similarity between the groups and the different letters express difference. significant $(\mathrm{p}>0.05)$. Baseline, 1, 3, 6 and 12 month attack frequency changes of the patients in group B receiving vitamin D at the beginning were statistically significant $(\mathrm{p}<0.05)$.

In Table 4, the comparison results of the attack frequency and PedMIDAS scores of the patients in group B are given in the subgroups of vitamin $\mathrm{D}$. In the patients with vitamin D level $\geq 20 \mathrm{ng} / \mathrm{mL}$, the change in the frequency of attacks at 3 months, 6 months and 12 months and PedMIDAS scores in the group were found to be statistically significant $(\mathrm{p}<0.001)$.

Descriptive statistics of pathological and normal EEG findings of the patients in the group $\mathrm{C}$ and the group D in Table 5 and the comparison results of EEG findings by groups and time are given in Table 6 . In the group C and the group D, considering 140 patients, there were focal or hemispheric spike or sharp wave activity in 13 patients $(9.3 \%)$ and bilateral or generalized spike or sharp wave activity in 12 patients $(8.6 \%)$, focal slowdown in 8 patients $(5.8 \%)$, bilateral slow-wave activity or ground rhythm irregularity in 5 patients (3.6\%).

In Table 6, EEG findings at 1st, 3rd, 6th and 12 th months between the groups and the change depending on time was not statistically significant $(p>0.05)$. Since there were no patients with normal baseline EEG findings in groups $\mathrm{C}$ and $\mathrm{D}$, they were not included in the analysis in C and D group comparisons and time-dependent changes.

Comparison of EEG findings in the group $\mathrm{C}$ and the group $\mathrm{D}$ according to migraine type and time, there was no statistically significant difference between the groups with and without aura in C and D groups for 1st, 3rd, 6th and 12th month EEG findings $(\mathrm{p}>0.05)$.

In the comparison of EEG findings in the group D (whether normal or pathological) for periods (1st, 3rd, 6th and 12th month) and vitamin D level (vitamin D level $<20 \mathrm{ng} / \mathrm{mL}$ and vitamin $\mathrm{D}$ level $\geq 20 \mathrm{ng} /$ $\mathrm{mL}$ ), no statistically significant difference was found both in and between the groups $(\mathrm{p}>0.05)$. 
Tab. 5. Descriptive statistics of pathological and normal EEG findings of patients in group C and D.

\begin{tabular}{lcc}
\hline Variables & \multicolumn{2}{c}{ Descriptive statistics } \\
\hline Group C & Baseline & 12 th month \\
Focal slowdown & $4(26.7)$ & - \\
Focal or hemispheric spike and sharp wave activity & $5(33.3)$ & $1(6.7)$ \\
Bilateral or generalized spike or sharp wave activity & $2(13.3)$ & - \\
Bilateral slow-wave activity or background rhythm irregulation & $4(26.7)$ & - \\
Normal & - & $14(93.3)$ \\
\hline Group D & Baseline & 12 th month \\
Focal slowdown & $4(15.4)$ & - \\
Alpha asymmetry & $1(3.8)$ & - \\
Focal or hemispheric spike or sharp wave activity & $8(30.8)$ & $1(3.8)$ \\
Bilateral or generalized spike or sharp wave activity & $10(38.5)$ & $2(7.7)$ \\
Photoparoxysmal response & $1(3.8)$ & - \\
Bilateral slow wave activity or background rhytm irregularity & $1(3.8)$ & - \\
Diffuse slow wave activity & $1(3.8)$ & $1(3.8)$ \\
Normal & - & $22(84.6)$ \\
\hline Da
\end{tabular}

Data are given as $\mathrm{n}(\%)$.

Tab. 6. Comparison of EEG findings by groups and time.

\begin{tabular}{|c|c|c|c|c|c|}
\hline \multicolumn{3}{|l|}{ Variables } & Group C & \multirow{2}{*}{$\begin{array}{c}\text { Group D } \\
26(100.0) \\
-\end{array}$} & \multirow{2}{*}{$\begin{array}{c}\mathrm{p}^{*} \\
- \\
-\end{array}$} \\
\hline \multirow{5}{*}{ EEG } & Baseline & $\begin{array}{l}\text { Pathological } \\
\text { Normal }\end{array}$ & $\begin{array}{c}15(100.0) \\
-\end{array}$ & & \\
\hline & 1st month & $\begin{array}{l}\text { Pathological } \\
\text { Normal }\end{array}$ & $\begin{array}{c}2(13.3) \\
13(86.7) \\
\end{array}$ & $\begin{array}{c}5(19.2) \\
21(80.8) \\
\end{array}$ & 0.958 \\
\hline & 3rd month & $\begin{array}{l}\text { Pathological } \\
\text { Normal }\end{array}$ & $\begin{array}{c}4(26.7) \\
11(73.3) \\
\end{array}$ & $\begin{array}{c}7(26.9) \\
19(73.1) \\
\end{array}$ & 0.999 \\
\hline & 6th month & $\begin{array}{l}\text { Pathological } \\
\text { Normal }\end{array}$ & $\begin{array}{c}4(26.7) \\
11(73.3) \\
\end{array}$ & $\begin{array}{c}2(7.7) \\
24(92.3) \\
\end{array}$ & 0.231 \\
\hline & 12th month & $\begin{array}{l}\text { Pathological } \\
\text { Normal }\end{array}$ & $\begin{array}{c}1(6.7) \\
14(93.3) \\
\end{array}$ & $\begin{array}{c}4(15.4) \\
22(84.6) \\
\end{array}$ & 0.744 \\
\hline$P$ & & & 0.234 & 0.158 & \\
\hline
\end{tabular}

Data are given as n (\%). p; shows the significance of difference between time periods and p* shows the significancy of difference between groups

\section{Discussion}

Headache is one of the most common neurological problems among children (9). Poyrazoğlu et al (10) reported that recurrent headache was detected in 5027 (47.5\%) of 10584 school children aged between 7 and 17. Primary recurrent headache frequency was reported as $21 \%$. They reported that migraine prevalence was $7.2 \%$ among primary recurrent headaches, and that $68 \%$ of the patients diagnosed with migraine were girls and $32 \%$ were boys (10). Song et al (11) evaluated 157 migraine patients in their study. They also reported that $75.2 \%$ of all the patients were girls, and the rate of vitamin D deficiency in girls was 94/118 (79.7\%), while this ratio was $27 / 39(69.2 \%)$ in boys.

In the present study, there was no statistically significant difference between the groups for age and migraine types (Tab. 1). However, there was a statistically significant difference between study groups for gender. In accordance with literature, $67.9 \%$ of the patients in the group B and $61.5 \%$ of the patients in the D group were girls. Besides, this finding may be related to the fact that vitamin D deficiency is more common in girls than boys due to our preservative society structure. These findings may also support the view that the prevalence of migraine in adolescent girls is a risk factor in the etiopathogenesis of vitamin $\mathrm{D}$ deficiency.

Guidetti et al (12) highlighted that migraine should not only be related to genetic and environmental factors and it is multifactorial. This multifactorial disease may have negative effects on children's school, family and social life. Therefore, studies on both pathogenesis and treatment of the disease continue. Many studies were conducted to assess the relationship between vitamin D and migraine. It was reported on vitamin D deficiency or insufficiency in migraine and headache patients. In the literature review by Ghorbani et al (13), it was stated that these rates vary between $45-100 \%$. In addition, vitamin $\mathrm{D}$ deficiency of migraine patients and the effectiveness of vitamin D in the treatment had been evaluated in recent years. It was reported that vitamin D improves the quality of life and improves headache scores in various studies (14).

Kilic and Kilic (15) evaluated 92 paediatric migraine patients in their study and divided the patients into two subgroups as low-level vitamin D and normal level vitamin D groups. In conclusion, they emphasized that there was a significant relationship between migraine in paediatric patients and vitamin D level. They also emphasized that vitamin $\mathrm{D}$ treatment is beneficial in migraine patients.

In the present study, a comparison of attack frequency and PedMIDAS scores of the patients within the groups A and B and between the two groups themselves are given in Table 2. Results similar to time-related improvement in the group A were also obtained in the group B. As it can be seen in Table 3, the comparison of PedMIDAS scores and attack frequencies of the patients, who did not receive treatment in the group A and those, who received vitamin D treatment in the group $\mathrm{B}$ were compared between the groups and by time. The median values of initial PedMIDAS scores and attack frequencies were 5.0 (3.0-10.5), $3.0(2.0-4.0)$ in the group A, and 14.5 (6.0-33.8), $6.5(4.0-12.0)$ respectively in the group $B$, and these values were in the group B. It was significantly higher $(p<0.05)$. While the temporal change of these values in the group B was also statistically significant $(p<0.05)$, there was no statistically significant change in the group A $(p>0.05)$. These findings support the view that the effect of vitamin D treatment on PedMIDAS scores and attack frequency is as effective as classical migraine treatment in the long term, similar to the studies of Kilic and Kilic (15). In addition, these findings support the view that clinical findings will be more severe in the patients with vitamin D deficiency.

Togha et al (16) reported that that vitamin D level should be evaluated in migraine patients and that every $5 \mathrm{ng} / \mathrm{mL}$ increase in 
serum vitamin D level would lead to a $22 \%$ proportional decrease in migraine frequency. They also emphasized that vitamin D level should be kept above $20 \mathrm{ng} / \mathrm{mL}$ in the patients. In the present study, in the patients with vitamin $\mathrm{D} \geq 20 \mathrm{ng} / \mathrm{mL}$, it was observed that the change of attack frequency and PedMIDAS scores over time in the group was statistically significant $(\mathrm{p}<0.001)$ and showed a continuous change (Tab. 4). Considering the literature data, these results may not be associated with migraine alone, but it suggests that deficiency or insufficiency of vitamin D may be a risk factor for migraine pathophysiology. Migraine patients should be followed up for vitamin D deficiency or insufficiency, vitamin $\mathrm{D}$ treatment should be given to the patients with deficiency and vitamin D level should be kept at a sufficient level ( $\geq 20 \mathrm{ng} / \mathrm{mL})$. The patients, who need migraine prophylaxis despite previous vitamin D treatment should also be evaluated for migraine prophylaxis treatment.

The association between migraine and epilepsy is a controversial topic. These two paroxysmal disorders may trigger one another or sometimes show a coexistence (17). The use of EEG as a diagnostic test in the patients presenting with headache is still a controversial issue. Dow and Whitty (18) reported dysrhythmia showing fluctuation in migraine phases in EEG of 51 migraine patients in 1947. This dysrhythmia has been reported to be associated with neuronal dysfunction of the trigeminovascular system (19). EEG abnormality in migraine patients had been reported in approximately $20 \%$ in the following years (20). Sand (21) reported in the review that focal slow-wave activity was detected in $0-15 \%$ of migraine patients with or without aura in the interictal period, and spike-wave activity in $0.2-9 \%$ of the patients. He stated that it was not different from the EEG findings in the control group. However, spike-wave activity was more common in migraine patients than in the control groups. In his study, slow-wave activity and background activity in migraine patients with aura indicated a depression in amplitude, unilateral or bilateral delta activity or a slowdown in hemiplegic migraine and basilar migraine patients. De Carlo et al (22) showed the EEG findings in the ictal phase in $32(80 \%)$ of 40 migraine patients and found that 29 patients had migraine with aura. The most common EEG findings were focal, hemispheric, or bilateral slowing. They reported that rapid beta activity was observed in the ictal period in $7.5 \%$ of the patients. In the interictal period, 357 (86.6\%) of 412 patients had normal EEG, 18 had $4.4 \%$ interictal period slow-wave activity, 30 patients (7.3\%) had epileptic activity. Also, rolandic spikes were detected in 4 of 30 patients with interictal epileptic activity. It was reported that 11 patients had normalized EEG findings, 8 patients had still EEG findings, and 4 of 8 patients were diagnosed with epilepsy and two patients had epilepsy history in their families. Golla and Winter (23) reported that the persistence of the photic drift response ( $\mathrm{H}$ response) can be seen in the patients with migrainelike headaches. Piccinelli et al (24) reported that they detected pathology in EEG at the rate of $43.5 \%$ in the interictal period of migraine patients with aura and $5.4 \%$ of migraine patients without aura. The most frequent interictal EEG findings were spike, sharp-wave, slow-wave, spike-slow-wave complex or multiple spike-wave activities $(20,24)$.
In the present study, similar to literature data, interictal EEG disorder was found in 41 (29.3\%) patients of the initial EEGs (Tab. 1). Descriptive statistics of the pathological and normal EEG findings of the patients in the groups $\mathrm{C}$ and $\mathrm{D}$ are given in Table 5. There were focal or hemispheric spike or sharp wave activity in 13 patients $(9.3 \%)$, bilateral or generalized spike or sharp wave activity in 12 patients $(8.6 \%)$, focal slowdown in 8 patients $(5.8 \%)$, bilateral slow-wave activity or ground rhythm irregularity in 5 patients $(3.6 \%)$. In the group $\mathrm{D}$, photoparoxysmal response was detected in interictal EEG at the beginning of the study in one patient. At the end of the study, EEG was pathological in one patient $(6.7 \%)$ in group $\mathrm{C}$ and four patients $(15.3 \%)$ in group D (5 of 140 patients, $3.6 \%$ ). The comparison results of the EEG findings by groups and time are given in Table $6(\mathrm{p}>0.05)$. In this study, $40 \%$ of the patients in group C and $46.2 \%$ of the patients in group $\mathrm{D}$ were migraines with aura. The temporal change in the EEG findings of migraine patients with and without aura was not statistically significant $(\mathrm{p}>0.05)$.

Considering this information, interictal EEG is not routinely recommended in the diagnostic evaluation of the patients with headache (21). However, it is stated that if the clinical findings of the patients cause a suspicion of epilepsy, it may have a diagnostic contribution (21). EEG scan is recommended in the patients with a suspected alternative hemiplegia, prolonged migraine aura and basillary migraine (21). In addition, if clinical history is suspected in terms of epilepsy, EEG may be performed for differential diagnosis (25).

The relationship between vitamin D and epilepsy is versatile (4). Sönmez et al (26) evaluated the patients with idiopathic epilepsy. They reported that $25-\mathrm{OH}$ vitamin-D3 levels were significantly lower in the patient group compared to the control group $(14.07 \pm 8.12$ and $23.38 \pm 12.80 \mathrm{ng} / \mathrm{mL})$.

Holló et al (27) measured vitamin D levels in 13 resistant epilepsy patients and normalized the vitamin D level with treatment. They reported that the frequency of seizures decreased by an average of $40 \%$ with vitamin $\mathrm{D}$ treatment and the normalization of serum vitamin D level had an anticonvulsant effect. It is emphasized that low vitamin D levels are associated with an increase in the frequency of seizures in the patients with epilepsy. Teagarden et al (28) evaluated vitamin D levels in 596 epilepsy patients in their study. They reported that vitamin D level was $<20 \mathrm{ng} / \mathrm{mL}$ in $45 \%$ of patients and $<10 \mathrm{ng} / \mathrm{mL}$ in $11 \%$. For this reason, in the patients using antiepileptics, it is recommended that vitamin D levels are routinely measured 2 or 3 times a year according to age groups $(27,28)$.

Rarely, there are reports that there is no correlation between vitamin D level and frequency of seizures (29). However, the general belief in literature is that vitamin $\mathrm{D}$ treatment has positive effects on decreasing seizure frequency (30). In recent years, it has been focused on the antiepileptic effects of vitamin $D$. It is stated that GABA (A) receptor modulation is also important in the antiepileptic effects of vitamin D (4). However, it is also noted that vitamin $\mathrm{D}$ is not as potent as a classic anticonvulsant (eg lorazepam) (31).

We did not find a study evaluating the relationship between vitamin D deficiency and EEG findings in literature search. How- 
ever, Danesi (32) suggested that photoparoxysmal changes in epilepsy patients were higher in the winter than in the summer, which may be related to seasonal changes in the amount of sunlight and strengthened this theory with the study of British and Nigerian Grand Mal epilepsy patients. In Nigerian patients, spike-wave discharges, photoparoxysmal changes, and non-specific EEG changes were seen by $15.7 \%$, whereas British patients with similar diagnoses reported this rate to be $52.9 \%$ (33). This finding supports the view that vitamin D deficiency or insufficiency may be associated with EEG findings in epilepsy patients. However, vitamin D level was not studied in the study of Danesi (33).

In the present study, we evaluated the relationship between EEG findings and vitamin D level in migraine patients. There was no statistically significant difference in the interictal EEG findings of the patients in the groups $\mathrm{C}$ and $\mathrm{D}$ during baseline, follow-up, and treatment $(p>0.05)$. EEG findings of migraine patients with and without aura in groups $C$ and D were not statistically significant between groups $(p>0.05)$. There was no statistical relationship between vitamin D level $(<20 \mathrm{ng} / \mathrm{mL}$ and $\geq 20 \mathrm{ng} / \mathrm{mL})$ and EEG findings in group D $(\mathrm{p}>0.05)$.

\section{Conclusions}

In conclusion, considering that literature highlights that vitamin D may play a role in both epilepsy and migraine pathogenesis as a neurosteroid and the pathophysiology of EEG changes, it should be taken into consideration. However, in the present study, no relation was found between interictal EEG findings and vitamin D level in migraine patients. In larger case series, the threshold value should be determined in migraine patients for vitamin D level, and it should be studied in the larger patient groups with EEG disorder and migraine coexistence, especially on attack frequency, PedMIDAS scores and EEG findings $(26,34,35)$.

\section{Highlights}

- Vitamin D deficiency is higher in girls compared to boys in migraine patients.

- The most common EEG findings was a focal or generalized spike/sharp wave activity.

- There was no statistical relationship between EEG findings and vitamin D levels.

\section{References}

1. Headache Classification Committee of the International Headache Society (IHS). The International Classification of Headache Disorders, 3rd edition (beta version). Cephalalgia 2013; 33 (9): 629-808.

2. Lewis DW. Headaches in Infants and Children. In: Swaiman KF, Ashwal S, Ferriero DM, Schor NF., editor. Swaiman's Pediatric Neurology Principles and Practice. 5th Ed. UK/USA, Elsevier Saunders; 2012: 881-899.

3. Verrotti A, Coppola G, Di Fonzo A, Tozzi E, Spalice A, Aloisi P, Bruschi R, Iannetti P, Villa MP, Parisi P. Should “migralepsy" be considered an obsolete concept? A multicenter retrospective clinical/EEG study and review of the literature. Epilepsy Behav 2011; 21 (1): 52-59.

4. Holló A, Clemens Z, Lakatos P. Epilepsy and vitamin D. Int J Neurosci 2014; 124 (6): 387-393.

5. Reddy DS. Role of neurosteroids in catamenial epilepsy. Epilepsy Res 2004; 62 (2-3): 99-118.

6. Kalueff AV, Minasyan A, Keisala T, Kuuslahti M, Miettinen S, Tuohimaa P. The vitamin D neuroendocrine system as a target for novel neurotropic drugs. CNS Neurol Disord Drug Targets 2006; 5 (3): 363-371.

7. Hershey AD, Powers SW, Vockell AL, LeCates S, Kabbouche MA, Maynard MK. PedMIDAS: development of a questionnaire to assess disability of migraines in children. Neurology 2001; 57 (11): 2034-2039.

8. Munns CF, Shaw N, Kiely M, Specker BL, Thacher TD, Ozono K, Michigami T, Tiosano D, Mughal MZ, Mäkitie O, Ramos-Abad L, Ward L, DiMeglio LA, Atapattu N, Cassinelli H, Braegger C, Pettifor JM, Seth A, Idris HW, Bhatia V, Fu J, Goldberg G, Sävendahl L, Khad. Global Consensus Recommendations on Prevention and Management of Nutritional Rickets. J Clin Endocrinol Metab 2016; 101 (2): 394-415.

9. Dao JM, Qubty W. Headache Diagnosis in Children and Adolescents. Curr Pain Headache Rep 2018; 22 (3): 17.

10. Poyrazoğlu HG, Kumandas S, Canpolat M, Gümüs H, Elmali F, Kara A, Per H. The prevalence of migraine and tension-type headache among schoolchildren in Kayseri, Turkey: an evaluation of sensitivity and specificity using multivariate analysis. J Child Neurol 2015; 30 (7): 889-895.

11. Song TJ, Chu MK, Sohn JH, Ahn HY, Lee SH, Cho SJ. Effect of Vitamin D Deficiency on the Frequency of Headaches in Migraine. J Clin Neurol 2018; 14 (3): 366-373.

12. Guidetti V, Cerutti R, Faedda N, Natalucci G. Migraine in childhood: an organic, biobehavioral, or psychosomatic disorder? Neurol Sci 2019; 40 (1): 93-98.

13. Ghorbani Z, Togha M, Rafiee P, Ahmadi ZS, Rasekh Magham R, Haghighi S, Razeghi Jahromi S, Mahmoudi M. Vitamin D in migraine headache: a comprehensive review on literature. Neurol Sci 2019; 40 (12): 2459-2477.

14. Al-Nimer MS. Vitamin D: Is it a primary hormone targeting the migraine headache or just as adjunct therapy? Neurosci (Riyadh) 2017; 22 (1): 69 .

15. Kilic B, Kilic M. Evaluation of Vitamin D Levels and Response to Therapy of Childhood Migraine. Med (Kaunas) 2019; 55 (7): 321.

16. Togha M, Razeghi Jahromi S, Ghorbani Z, Martami F, Seifishahpar M. Serum Vitamin D Status in a Group of Migraine Patients Compared with Healthy Controls: A Case-Control Study. Headache 2018; 58 (10): $1530-1540$.

17. Kasteleijn-Nolst Trenité DG, Verrotti A, Di Fonzo A, Cantonetti L, Bruschi R, Chiarelli F, Villa MP, Parisi P. Headache, epilepsy and photosensitivity: how are they connected? J Headache Pain 2010; 11 (6): 469-476.

18. Dow DJ, Whitty CW. Electroencephalographic changes in migraine; review of 51 cases. Lancet. 1947; 2 (6463): 52-54.

19. Welch KM. Contemporary concepts of migraine pathogenesis. Neurology 2003; 61 (8 Suppl 4): 2-8.

20. Nejad Biglari H, Rezayi A, Nejad Biglari H, Alizadeh M, Ahmadabadi $\mathbf{F}$. Relationship between migraine and abnormal EEG findings in children. Iran J Child Neurol 2012; 6 (3): 21-24. 
21. Sand T. Electroencephalography in migraine: a review with focus on quantitative electroencephalography and the migraine vs. epilepsy relationship. Cephalalgia 2003; 23 (1): 5-11. Erratum in: Cephalalgia 2003; 23 (6): 483

22. De Carlo L, Cavaliere B, Arnaldi C, Faggioli R, Soriani S, Scarpa P. EEG evaluation in children and adolescents with chronic headaches. Eur J Pediatr. 1999; 158 (3): 247-248.

23. Golla FL, Winter AL. Analysis of cerebral responses to flicker in patients complaining of episodic headache. Electroencephalogr Clin Neurophysiol. 1959; 11 (3): 539-549.

24. Piccinelli P, Borgatti R, Nicoli F, Calcagno P, Bassi MT, Quadrelli M, Rossi G, Lanzi G, Balottin U. Relationship between migraine and epilepsy in pediatric age. Headache 2006; 46 (3): 413-421.

25. Sandrini G, Friberg L, Coppola G, Jänig W, Jensen R, Kruit M, Rossi P, Russell D, Sanchez del Rìo M, Sand T, Schoenen J; European Federation of Neurological Sciences. Neurophysiological tests and neuroimaging procedures in non-acute headache (2nd edition). Eur J Neurol 2011; 18 (3): 373-381.

26. Sonmez FM, Donmez A, Namuslu M, Canbal M, Orun E. Vitamin D Deficiency in Children with Newly Diagnosed Idiopathic Epilepsy. J Child Neurol 2015; 30 (11): 1428-1432.

27. Holló A, Clemens Z, Kamondi A, Lakatos P, Szúcs A. Correction of vitamin D deficiency improves seizure control in epilepsy: a pilot study. Epilepsy Behav 2012; 24 (1): 131-133.
28. Teagarden DL, Meador KJ, Loring DW. Low vitamin D levels are common in patients with epilepsy. Epilepsy Res 2014; 108 (8): 1352-1356.

29. Brandt AM, Doherty MJ. VEEG models of seizure frequency - do SSRI medications or vitamin D supplements alter seizure collections? Epilepsy Behav 2014; 41: 208-209.

30. Clemens Z, Holló A. Comment on "VEEG models of seizure frequency - Do SSRI medications or vitamin D supplements alter seizure collections?". Epilepsy Behav 2015; 45: 81.

31. Doherty M, Brandt A. Response to drs. Hollo and clemens. Epilepsy Behav 2015; 45: 82.

32. Danesi MA. Seasonal variations in the incidence of photoparoxysmal response to stimulation among photosensitive epileptic patients: evidence from repeated EEG recordings. J Neurol Neurosurg Psychiatry. 1988; 51 (6): $875-877$.

33. Danesi MA. Electroencephalographic manifestations of grand mal epilepsy in Africans: observation of relative rarity of interictal abnormalities. Epilepsia. 1988; 29 (4): 446-450.

34. Donmez A, Orun E, Sonmez FM. Vitamin D status in children with headache: A case-control study. Clin Nutr ESPEN 2018; 23: 222-227.

35. Fernandes de Abreu DA, Eyles D, Féron F. Vitamin D, a neuroimmunomodulator: implications for neurodegenerative and autoimmune diseases. Psychoneuroendocrinology 2009; 34 (1): 265-277.

Received September 15, 2021. Accepted September 21, 2021. 